\title{
SEMANTIC EMERGENCE AS A TRANSLATION PROBLEM
}

\author{
Svetlana V. Serebryakova \\ North-Caucasus Federal University, Stavropol, Russian Federation \\ Aleksandra I. Milostivaya \\ North-Caucasus Federal University, Stavropol, Russian Federation
}

\begin{abstract}
The article deals with the hermeneutic analyses of the intertextual passages from the novel Ulysses by J. Joyce in the original and translation as a theoretical base of which the principle of palimpsest is considered, i.e. simultaneous sounding in the target text of the "voices" of the source text author, the narrator, characters of the original and prototext-sources of intertextual passages. It has been found that there is an emergence of implicit meanings in the original version, that is seen in the presence in the integral text of the analyzed chapter Oxen of the Sun of special communicative overtones, lacking in some separate constituent propositions of it. Linguistic and extralinguistic means, which retain the semantic emergence at the level of content-conceptual information and implication in the target text, are studied. It is shown that semantic emergence of the target text is fulfilled when the translator aims at an ideal elite reader (the translation by V.A. Khinkis and S.S. Khoruzhiy) and is not conveyed in case the puristic approach to the target language is actualized as the thesaurus of an average reader doesn't transfer the language play of palimpsests layers (translation by S.A. Makhov), and thus can't be considered as communicatively adequate.
\end{abstract}

Key words: semantic emergence, translation, fiction text, intertextuality, implicit meaning, palimpsest principle, J. Joyce, novel Ulysses.

Citation. Serebryakova S.V., Milostivaya A.I. Semantic Emergence as a Translation Problem. Vestnik Volgogradskogo gosudarstvennogo universiteta. Seriya 2, Yazykoznanie [Science Journal of Volgograd State University. Linguistics], 2017, vol. 16, no. 3, pp. 48-57. (in Russian). DOI: https://doi.org/10.15688/jvolsu2.2017.3.5

\section{СЕМАНТИЧЕСКАЯ ЭМЕРДЖЕНТНОСТЬ КАК ПЕРЕВОДЧЕСКАЯ ПРОБЛЕМА}

\author{
Светлана Васильевна Серебрякова \\ Северо-Кавказский федеральный университет, г. Ставрополь, Российская Федерация \\ Александра Ивановна Милостивая \\ Северо-Кавказский федеральный университет, г. Ставрополь, Российская Федерация
}

\begin{abstract}
Аннотация. В статье на основе герменевтического анализа интертекстуальных пассажей из романа Дж. Джойса «Улисс» в оригинале и переводных версиях на русский язык рассматривается транслатологическая проблема реализации принципа палимпсеста - одновременного звучания в тексте-трансляте «голосов» автора исходного текста, повествователя-нарратора, персонажей текста оригинала и прототекстов источников интертекстуальных пассажей - и возникающей при этом эмерджентности. На материале одной главы романа («Oxen of the Sun» - «Быки солнца») показано, что в тексте оригинала семантическая эмерджентность имплицитных смыслов создается особыми коммуникативными обертонами, отсутствующими у отдельных конституирующих его пропозиций. Описано, с использованием каких лингвистических и паралингвистических средств обеспечивается сохранение в переводах семантической эмерджентности на уровне
\end{abstract}


содержательно-концептуальной информации и подтекста. Установлено, что семантическая эмерджентность рассматриваемого текста-транслята реализуется в тех случаях, когда переводчик ориентирован на идеального элитарного читателя (перевод В.А. Хинкиса и С.С. Хоружего), и не сохраняется в тех случаях, когда переводчик ориентируется на пуристический подход к переводящему языку, тезаурус рядового читателя и не передает языковой игры пластов палимпсеста (перевод С.А. Махова), следовательно, такая трансляция не может считаться коммуникативно адекватной оригиналу.

Ключевые слова: семантическая эмерджентность, перевод, художественный текст, интертекстуальность, имплицитный смысл, принцип палимпсеста, Дж. Джойс, роман «Улисс».

Цитирование. Серебрякова С.В., Милостивая А.И. Семантическая эмерджентность как переводческая проблема // Вестник Волгоградского государственного университета. Серия 2, Языкознание. - 2017. - Т. 16, № 3. - C. 48-57. - DOI: https://doi.org/10.15688/jvolsu2.2017.3.5

\section{1. Текст как объект}

\section{лингвопереводоведческой рефлексии}

В последние десятилетия получили признание новые подходы к тексту как «языку в действии», речевому знаку высшего уровня и в то же время открытому динамическому явлению. Изучение целостного текста литературного произведения в контексте феноменологии культуры в самом широком смысле по праву занимает в современной филологической науке центральное место, при этом в фокус исследовательского интереса попадает не обособленное явление, изолированное от других единиц, а явление в различных социокультурных контекстах, что чрезвычайно актуально для обеспечения адекватности перевода.

Текст выступает базовым объектом не только лингвистического, но и транслатологического анализа. М.М. Бахтин справедливо полагал, что текст представляет собой «первичную данность» для всех гуманитарных наук, будучи «той непосредственной действительностью, действительностью мысли и переживания, из которой только и могут исходить эти дисциплины и это мышление. Где нет текста, там нет и объекта для исследования и мышления» [Бахтин, 1986, с. 281].

Выявление на уровне языковых знаков специфических характеристик текста литературного произведения, в особенности семантическая интерпретация его лексем и синтаксических конструкций, составляет важный этап, предшествующий лингвопереводческому, лингвокультурологическому и литературоведческому анализу. В рамках филологии постулируется «анализ языка как элемента искусства всего произведения», что предполагает изучение таких его параметров, как ис- торизм, антропоцентричность, культурологическая направленность, комплексный, интегральный характер, лексикоцентричность [Болотнова, 2007, с. 25-26].

Культурологический и семиотический аспекты анализа литературного произведения релевантны для филологии, как и его традиционное, языковедческое понимание, поскольку все зафиксированное в письменной форме приобретает социокультурную релевантность, превращаясь в текст. Исследуя специфику различных аспектов культурной коммуникации, Н.Ф. Алефиренко констатирует, что культурологическая ценность текста состоит в том, что он «несет не только информацию для непосредственно общающихся, но и способен включаться в смысловые связи с другими текстами. Это значит, что такой текст приобретает новое качество: из системы реальной коммуникации (обмена сообщениями) говорящего и слушающего преобразуется в продукт культурной коммуникации - дискурс» [Алефиренко, 2002, с. 99] и шире - в «процесс текстового обмена между различными национальными культурами или ареалами» [Лотман, 2002 , c. 204].

Подобно другим структурам, специально генерируемым для «запечатления мысли», текст художественного произведения обладает ярко выраженной семиотической функцией, ибо она является базисной при возникновении вербального смысла. Поэтому аксиоматично то, что литературное произведение на семиотическом уровне рассматривается в науке как «вторичная моделируемая система», где отражение объективного мира и фикциональный писательский замысел находятся в отношениях дополнительности и могут быть истолкованы как единство системного и ин- 
дивидуального. Помимо этого, тексты такого жанра, как роман, - «миросозерцательно значимые и личностно окрашенные» [Хализев, 1999, с. 243] - содержат концептуальную информацию, связанную с эксплицитной и имплицитной оценкой, поскольку за каждым текстом стоит языковая личность его автора, «стремящаяся в своей речевой деятельности воплотить характерный для ее самосознания идеал, который отражает идеи культуры данного времени и данного народа» [Диброва, 1996, с. 3]. Прагматика литературного текста манифестируется не только в его воздействии на реципиента, но и в том, что текст содержит имплицитную информацию об авторе и сфере коммуникации.

Современной филологической науке свойственно столь важное для переводоведения стремление преодолеть практику «атомарного» изучения текстового пространства, изолированного исследования его структуры, семантики и прагматики. Всеобщее признание находит тезис о «необходимости комплексного, синтетического рассмотрения природы художественного текста, преодолевающего поаспектное, поуровневое его изучение» [Бабенко, Васильев, Казарин, 2000, с. 10]. Известный исследователь структуры и семантики художественного текста Л.Г. Бабенко отмечает, что именно сегодня получает реализацию давно провозглашенная идея комплексного изучения текста как своего рода универсума знания и познания, так как накоплено большое количество научных данных в области лингвистики текста, что позволяет осуществить «систематизацию, обобщение, синтез всего полезного, интересного и плодотворного, полученного при рассмотрении текста с разных позиций и подходов» [Бабенко, Васильев, Казарин, 2000, с. 10-11].

В наших рассуждениях мы исходим из того, что текст представляет собой не только ту среду, где реализуются значения слов и пропозиций. В переводческой плоскости речь должна идти об изучении семантики, различных (эксплицитных и имплицитных) репрезентаций «тотального смысла» всего текста. Исходным при этом является тезис о понимании текста как комплексной единицы коммуникативного процесса, обладающей сложной семантической и формально-граммати- ческой структурой, элементы которой, образуя в текстовом пространстве особые системные отношения, генерируют качественно новый персуазивный эффект. Ю.М. Лотман подчеркивал значимость подобной смыслообразующей функции художественного текста: он выступает «не в качестве пассивной упаковки заранее заданного смысла, а как генератор смыслов» [Лотман, 2002, с. 189].

Трактовка художественного текста как «устойчивой, завершенной, замкнутой системы, сформированной на основе динамического взаимодействия языковых элементов, репрезентирующих личностные смыслы» [Пищальникова, 1992, с. 59], позволяет нам допустить, что в тексте литературного произведения эксплицируется не единый глобальный смысл, а система отдельных иерархически организованных смыслов. Исходя из данных соображений, уместной представляется аналогия художественного текста с особой идеально-материальной субстанцией, инкорпорирующей элементы от вербальных до ментальных, которые вступают во взаимодействие, и только в рамках целостной системы они обладают тем смыслом, который интендирован писателем. При этом релевантной является мысль Б.М. Гаспарова о парадоксальной природе вербального сообщения как текста: оно «представляет собой единство, замкнутое целое, но это такое единство, которое возникает из открытого, не поддающегося полному учету взаимодействия... множества факторов, и такое замкнутое целое, которое способно индуцировать и впитывать в себя открытую, уходящую в бесконечность работу мысли» [Гаспаров, 1996, с. 321]. Развивая идеи Б.М. Гаспарова, М.Я. Дымарский понимает текст как «особую, развернутую вербальную форму осуществления речемыслительного произведения» [Дымарский, 2001, c. 36].

Итак, художественный текст являет собой единое смысловое целое, поэтому семантика всех его элементов взаимосвязана и подчинена целостному макросмыслу литературного произведения. Основные параметры текста любого типа - это цельность и связность, а следовательно, понимание отдельных пропозиций детерминировано их местом, ролью и функциями в целостном текстовом простран- 
стве, которое генерирует писательская интенция, так как именно в рамках всего фикционального мира литературного произведения актуализируется контекстуальное значение всех отдельных языковых средств.

При переводе, как известно, неизбежны объективные потери информации и при их оценке действует принцип примата целого над частью, который позволяет пожертвовать менее существенными деталями ради успешной передачи глобального содержания текста. Р. Барт предлагает признать за ситуацией, с которой связан референциальной соотнесенностью когерентный текст, «статус полноправного компонента его структуры» [Барт, 2001, с. 173]. Именно коммуникативные ситуации генерирования и восприятия литературного произведения, а также писательское мировидение являются основой генезиса художественного текста как связного, целостного и завершенного вербального произведения, где находит свою реализацию указанный принцип, столь важный при передаче имплицитного смысла текста как инварианта перевода.

\section{2. Принцип палимпсеста как базис для вербализации глубинного смысла исходного текста в переводе}

Для теории и практики перевода актуальна проблема передачи многослойной глубинной структуры содержания текста. Собственно вербальное содержание пропозиции - это поверхностное, прямое значение, которое определяется набором языковых элементов, изображающих типовую ситуацию. Языковое содержание художественного текста представляет собой лишь первый слой его глубинной структуры, хотя глобальный макросмысл литературного произведения декодируется из него и через него. Референциальная соотнесенность высказывания с конкретной ситуацией и контекстуальная детерминация его семантики способствуют экспансии содержательно-фактуальной, концептуальной и подтекстовой информации, которая присутствует в художественном тексте. Очевидно, что контекстуализация пропозиции - это базис вербальной коммуникации, обязательное условие функционирования языка в качестве средства межличностной интеракции и главная составляющая переводческого процесса.

Кроме того, при переводе имеет место передача дополнительного содержания, ассоциативно когерентного с языковым значением, т. е. подтекстовой информации, или имплицитных смыслов, не выраженных вербальными средствами. В.Н. Комиссаров полагает в этой связи, что «имплицитный смысл выводится из выраженного смысла и тем самым отличается от пресуппозиции, которая предшествует выраженному смыслу и служит логическим условием истинности сообщения» [Комиссаров, 2001, с. 59-60]. Передача имплицитного смысла, в первую очередь на текстовом уровне, - одна из наиболее значимых транслатологических проблем, ибо он, эксплицируя писательскую интенцию, может оказаться самым релевантным в литературном произведении, оставаясь на уровне глубинной структуры текста.

Процесс переводческого декодирования имплицитного смысла художественного произведения еще более усложняется в том случае, когда в составе текста оригинала присутствуют интертекстуальные пассажи. В этой ситуации переводчик, будучи активным субъектом, организующим сложную сеть диалогических взаимодействий автора исходного текста, его читателя и интертекста, производит поиск структурно эквивалентных и коммуникативно адекватных единиц в переводящем языке посредством моделирования фреймов речемыслительных практик автора оригинала, повествователя-нарратора и персонажей. В их пространстве абдуктивным путем выдвигаются гипотезы касательно оптимального соотношения эквивалентности и адекватности избранных вариантов.

В современном переводоведении справедливо отмечается, что подобный процесс когнитивного переводческого поиска нелинеен, поскольку в сознании переводчика «постоянно возникают ассоциации, новые мысли и логические связи, активируются различные фреймы знаний, одни направления поиска продолжаются, другие блокируются. В результате переводчику удается найти удовлетворительные, хотя и не всегда идеальные решения» [Гурова, 2010, с. 163]. Следствием гиперориентированости перевода текста, содержа- 
щего интертекстуальные пассажи, по отношению к потенциальному реципиенту может являться «нюансировка» семантики текстатранслята в целях гармонизации со скопосом как прагмафункциональным ориентиром переводческого мировосприятия, что предоставляет возможность «переводить один и тот же текст по-разному в зависимости от цели перевода и характера данного переводчику заказа» [Минченков, 2007, с. 32].

Для определения переводческой деятельности подходит метафора палимпсеста, о чем впервые написал французский структуралист Ж. Женетт. По словам английского писателяромантика Т. де Квинси, человеческий мозг это аналог огромного палимпсеста, который представляет собой «пергамент, с которого слой за слоем стирают первоначальную надпись с тем, чтобы нанести другую, причем более ранняя информация не исчезает бесследно, а как бы просвечивает сквозь новую, и ее смысл возможно декодировать» [Квинси, 2000, с. 152].

\section{3. Опыт интерпретации эмерджентности в русских переводах романа Дж. Джойса «Улисс»}

Задачей данной статьи является исследование перевода интертекстуальных пассажей в художественном текстовом пространстве как эмерджентной производной палимпсеста речемыслительных практик автора оригинала, повествователя-нарратора, описываемых персонажей в исходном тексте и прототексте - источнике интертекстуальности.

Наши теоретические рассуждения мы проиллюстрируем на примере одной из глав романа Дж. Джойса «Улисс» и двух ее переводов на русский язык, выполненных В.А. Хинкисом и С.С. Хоружим (1989) и С.А. Маховым (2007). Анализируемый нами фрагмент глава «Быки солнца» (Oxen of the Sun) - ocoбенно интересен в переводческом плане. В главе действие происходит в родильном доме, где Леопольд Блум, главный персонаж романа, проведывает знакомую женщину, недавно разрешившуюся от бремени, и где случайно оказывается Стивен Дедал, который и начинает разговор о вопросах продолжения рода. Так, в нарративном фокусе оказывает- ся эмбрион, процесс рождения и развития которого изображен в тексте главы как история становления английского языка с древнейших времен до начала XX века. При этом Дж. Джойс использует прием стилизации, порождая вторичные тексты, например, пародии на труды епископа Эльфрика, сочинения Дж. Мильтона, Л. Стерна, Дж. Свифта, Т. Маколея, Т. де Квинси, Ч. Диккенса и др. Очевидно, что такая частотность интертекстуальных пассажей является серьезной проблемой для переводчика.

Рассматриваемая глава из «Улисса» характеризуется эмерджентностью имплицитных смыслов в оригинале, которая должна быть в полной мере декодирована переводчиком и отображена в тексте-трансляте. Подобная эмерджентность предполагает «наличие у системного целого особых свойств, не присущих его подсистемам и блокам, а также сумме элементов, не объединенных системообразующими связями. Краткое античное определение: целое больше суммы его частей» [Реймерс, 1990, с. 608]. Американские ученые П. Ватцлавик, Ж. Бивин и Д. Джексон считают эмерджентность базовым принципом, организующим человеческую коммуникацию [Watzlawick, Beavin, Jackson, 2003, S. 121]. Коммуникативная сущность деятельности переводчика позволяет экстраполировать понятие эмерджентности в сферу переводоведения. Аксиоматично, что завершенный текст литературного произведения является единицей перевода и обладает эмерджентными свойствами (персуазивный эффект его не равен сумме персуазивных эффектов его пропозиций - авторской оценки, персонажной речи и т. д.). Это наблюдается и в переводе, когда «вследствие несовпадения индивидуальных концептуальных систем автора исходного текста и переводчика в переводимый текст вносятся дополнительные коннотации оценочного характера, отсутствующие в пропозициональном составе оригинала» [Милостивая, 2014, c. 198].

Возможный путь отображения игры эмерджентного смысла анализируемой главы из романа Дж. Джойса «Улисс» наметил С.С. Хоружий: «Общий принцип выбирать не приходится - историю может передать лишь история, стиль и язык должны меняться от 
древних истоков до современного жаргона. И, слава Богу, история русского литературного языка, от киевских и болгарских истоков до символизма и жаргона начала века (дальнейшее не касается нас), по разнообразию стилей и словарей, по диапазону произошедших изменений, смело выдерживает сравнение с любым из новых языков Европы» [Хоружий, 2004, с. 913]. Замена пародируемых текстов на исходном языке их историческими аналогами в переводящем неизбежно ведет к эффекту палимпсеста, когда в переводе в полной мере изображается эмерджентный имплицитный смысл оригинала и на фоне переводного метатекста проступает контур как джойсовской стилизации, так и ее прототекста, в основном англоязычного.

Другой переводчик «Улисса» на русский язык, С.А. Махов, скептически оценивает целесообразность принципа поиска подобий в англоязычной литературе при трансляции пародий и стилизаций Дж. Джойса, иллюстрирующих развитие эмбриона, отождествляемое с литературным творчеством. С.А. Махов предлагает компенсационную замену, фокусируясь на другом концептуальном лейтмотиве «Улисса» - идее о необходимости сохранения как высшей ценности национальной самобытности родной страны писателя - Ирландии, которая в период написания романа была английской колонией. В соответствии с логикой С.А. Махова, постепенная утрата ирландцами национальной идентичности связана с выходом из употребления их родного гэльского языка, а следовательно, необходимо уделять больше внимания сохранению чистоты родного русского языка, который выступает в рассматриваемом случае в качестве переводящего.

Несмотря на кажущуюся логичность и языкотворческую нетривиальность, подход С.А. Махова обедняет концептуальную суть «Улисса», построенного по принципу параллелизма в описании интеллектуальных поисков элитарной языковой личности и обостренного национального самосознания малого народа (ирландцев) на краю европейской цивилизации. Этот национально-патриотический мотив анализируемого романа выступает в качестве доминанты при построении текстовой структуры в переводе С.А. Махова, а мотив языко- вой элитарности, выраженный у Дж. Джойса при помощи многочисленных стилизаций, переводчик не только не принимает во внимание, но и, как показывает данный им метапоэтический комментарий, сознательно избегает. Между тем мотив языковой элитарности более значим, поскольку «Улисс» - это произведение для избранных и равняться на фоновые знания рядового читателя при его переводе не стоит: «Джойс мечтал об идеальном читателе, который посвятит всю жизнь чтению, изучению, расшифровке “Улисса". Не без иронии и даже некоторого злорадства он говорил, что насытил свой текст таким количеством загадок, что ученые, комментаторы, критики, литературоведы будут до скончания своих дней биться над их разгадкой» [Гениева, 1989, с. 177].

Итак, обратимся к выявлению эмерджентности и способов ее создания в оригинале и двух переводах главы «Быки солнца».

В первом из приводимых нами фрагментов Дж. Джойс стилизует текст под средневековую латинскую хронику, символизирующую для писателя первооснову английского языка:

It is not why therefore we shall wonder if, as the best historians relate, among the Celts, who nothing that was not in its nature admirable admired, the art of medicine shall have been highly honoured (Joyce, p. 501).

А посему нет резонов нам повергаться в недоумение, ежели, как надежнейшие летописания повествуют, меж кельтами, не в обычае коих было нечто превозносить, по естеству своему превознесения не достойное, искусство врачевания всемерно почитаемо было (Хинкис, Хоружий, с. 416).

В результате нет резонов нам фраппироваться, если, как информируют самые первоклассные источники, в кельтском сочиуме, не в менталитете которого было симпатизировать чему-либо, по натуре своей к симпатии непрезентабельному, медицина фантастически культивируема была (Махов, с. 369).

В исходном тексте латинский прототекст имитирован при помощи сложной периодической структуры предложения с пристрастием к гипотаксису и пассиву, характерной для латыни классического периода. При этом связи между его компонентами осуществляются при помощи союзов, нередко возвышенного 
стилистического регистра (therefore). У Джойса также широко представлены аллитерации, которые связывают ключевые понятия с доминантной смысловой насыщенностью (admirable admired, the art of medicine).

В переводе В.А. Хинкиса и С.С. Хоружего на передний план выходит именно воссоздание формальных языковых особенностей оригинала и сквозь его призму - латинского прототекстуального источника. Это достигается как при помощи калькирования синтаксического рисунка исходного текста, так и путем включения в перевод архаичных подчинительных союзов (посему, ежели) в сочетании с иной лексикой, обладающей возвышенными коннотациями (повергаться в недоумение, меж кельтами, по естеству своему превознесения не достойное, искусство врачевания) и являющейся заимствованиями из латыни (резон от фр. raison, от лат. ratio - «разум»). В целом игра пластов палимпсеста, изображающая эмерджентность совокупности смыслов транслируемых единиц оригинала, в проанализированном переводе передана довольно четко.

В переводе С.А. Махова реализован иной подход к изображению стилизованной латинской хроники: сделан упор, прежде всего, на экспликацию архаики, отождествляемой в его понимании с заимствованиями в русском языке, сквозь которые впоследствии «прорастет» исконная родная речь: в процитированном выше текстовом пассаже все лексемы, кроме служебных, иноязычного происхождения. Подобный пуристический переводческий прием усилен паралингвистически: стилизованный текст дается другим шрифтом и синим цветом, который в системе координат С.А. Махова символизирует исток, начало жизни. Далее, с развитием повествования об эмбрионе-языке, в текст постепеннно все чаще вкрапляются набранные черным славянские слова, перевод становится сине-черным, а впоследствии и полностью традиционным - черным на белом листе бумаги, напечатанным классическим шрифтом. Следовательно, здесь преобладает ориентация на семиотику текста перевода, а не прототекста при пресуппонировании невозможности существования «идеального» читателя, способного и жела- ющего вникнуть во все тонкости элитарной языковой игры Дж. Джойса.

Следующий пародируемый Дж. Джойсом текстовый фрагмент восходит к такому прототектуальному источнику, как «Путешествия сэра Джона Мандевилля», представляющему собой «сборник легенд о путешествиях, написанный в Бельгии в XIV в. по-французски и в XV в. известный также в английском переводе, который был популярен и снискал автору титул “отца английской прозы”» [Хоружий, 2004, с. 915]:

And the traveller Leopold said that he should go otherwhither for he was a man of cautels and a subtile. Also the lady was of his avis and repreved the learningknight though she trowed well that the traveller had said thing that was false for his subtility. But the learningknight would not hear say nay nor do her mandement ne have him in aught contrarious to his list and he said how it was a marvellous castle (Joyce, p. 504-505).

И Леополд странный рече еже достоит ему инуду отити яко же бе муж потаен и лукав. Такоже и госпожа согласие с тем восприя и укори ученика сего аще и добре разуме яко странный сей прорече лоная словеса ради лукавства его. Обаче ученик тый не хотяще ни слышати ниже покориться госпоже ниже прияти противное его желанию и глагола яко храмина сия чюдна есть (Хинкис, Хоружий, с. 419).

А Леопольд-паломник парировал, что должен он наведаться в альтернативньй пункт, потому что был он тактичный и корректный. И леди была с ним солидарна и реприманду эрудированного рыщаря подвергла, хотя она идеально в курсе была, что визитер из-за деликатности своей сфальшивил. Но рыщарь эрудированный проигнорировал и его изоляционизм, и ее критику, и вообще минимальную оппозииию своему импульсу и отрекомендовал эту келью как шикарнуюо (Махов, с. 372).

Дж. Джойс создает свою стилизованную пародию посредством вкраплений французских варваризмов (avis - фр. «мнение, мысль»; mandement - фр. уст. «предписание, указ, повеление»; repreve - от фр. reprimande ср.: лат. reprimenda, от reprimare - «выговор, внушение») и устаревшей лексики среднеанглийского происхождения (otherwither - elsewhere в современном англ.; nay - not; cautel - «такт, манера» от среднефр. cautele, ср.: лат. cautela). 
В переводе В.А. Хинкиса и С.С. Хоружего все еще чувствуются нотки архаики XIV в., которым датирован прототекст стилизации: это отдаленное прошлое, а потому в их переводном тексте множество древнерусских лексем (инуду - «в иное место», бе аорист от быти и др.) и грамматических конструкций (ниже - «ни же», иже суть - «какие есть» и др.). В целом перевод можно признать коммуникативно адекватным оригиналу и отметить то, что временной пласт в текстах на исходном и переводящем языках совпадает.

Переводчик С.А. Махов в анализируемом пассаже следует своей логике, используя паралингвистические (графические) средства: в созданном им тексте среди заимствованных слов, набранных нетрадиционным шрифтом синего цвета, появляются «черные» славянские лексемы (наведаться, подвергла, вообще), представляющие собой маркеры приближения к современности.

\section{Выводы}

Подводя итог изучению семантической эмерджентности, отметим релевантность данного понятия для транслатологии, что обусловлено коммуникативной природой переводческой деятельности. Целостный когерентный художественный текст выступает в качестве единицы перевода и обладает эмерджентными свойствами, поскольку персуазивный эффект литературного произведения, как правило, превосходит сумму персуазивных эффектов составляющих его отдельных высказываний оценки автора и нарратора, персонажной речи и т. д. Наблюдения над эмпирикой показали, что наиболее четко эмерджентность манифестируется в художественном переводе при передаче имплицитной информации вообще и интертекстуальных пассажей в частности.

Исследование вербализованной речемыслительной деятельности автора оригинала, повествователя-нарратора и персонажей на материале фрагмента из романа Дж. Джойса «Улисс» и двух его переводов на русский язык позволяет сделать вывод о том, что в полном объеме эмерджентность в организации текстатранслята связана с вербализацией доминантного для Дж. Джойса мотива интеллектуаль- ных поисков элитарной языковой личности, что присутствует в переводе романа у В.А. Хинкиса и С.С. Хоружего. Перевод «Улисса» С.А. Махова, где вследствие пуристического подхода к переводящему языку и ориентации на тезаурус рядового читателя не передана вся полнота обертонов многомерного смысла, задуманного автором оригинала, не может считаться коммуникативно адекватным.

\section{СПИСОК ЛИТЕРАТУРЫ}

Алефиренко, Н. Ф. Поэтическая энергия слова. Синергетика языка, сознания и культуры / Н. Ф. Алефиренко. - М. : Академия, 2002. - 394 с.

Бабенко, Л. Г. Лингвистический анализ художественного текста / Л. Г. Бабенко, И. Е. Васильев, Ю. В. Казарин. - Екатеринбург : Изд-во Урал. ун-та, 2000. $-534 \mathrm{c}$.

Барт, Р. Лингвистика текста / Р. Барт // Текст: аспекты изучения семантики, прагматики и поэтики : сб. ст. - М. : УРСС, 2001.- С. 168-175.

Бахтин, М. М. Эстетика словесного творчества / М. М. Бахтин. - М. : Искусство, 1986. - 444 с.

Болотнова, Н. С. Филологический анализ текста / Н. С. Болотнова. - М. : Флинта : Наука, 2007. $-520 \mathrm{c}$.

Гаспаров, Б. М. Язык, память, образ. Лингвистика языкового существования / Б. М. Гаспаров. М. : Новое лит. обозрение, 1996. - 352 с.

Гениева, Е. Ю. Комментарии к «Улиссу» / Е. Ю. Гениева // Иностранная литература. 1989. - № 1. - С. 177-186.

Гурова, Ю. И. Перевод. Воссоздание внутренней смысловой программы и единого смысла текста как основа моделирования процесса перевода / Ю. И. Гурова. - СПб. : Реноме, 2010. - 239 с.

Диброва, Е. И. Феномены текста: культурофилологический и психофилологический / Е. И. Диброва // Philologica. - 1996. - № 10. - С. 2-5.

Дымарский, М. Я. Проблемы текстообразования и художественный текст (на материале русской прозы XIX-XX вв.) / Е. И. Дымарский. - М. : УРCC, 2001. $-328 \mathrm{c}$.

Квинси, Т. де. Исповедь англичанина, любителя опиума / Т. де Квинси. - М. : Ладомир : Наука, $2000 .-422 \mathrm{c}$.

Комиссаров, В. Н. Современное переводоведение / В. Н. Комиссаров. - М. : ЭТС, 2001. -424 с.

Лотман, Ю. М. История и типология русской культуры / Ю. М. Лотман. - СПб. : Искусство-СПб., 2002. $-768 \mathrm{c}$.

Милостивая, А. И. Роль принципов синергетики в современном переводоведении / А. И. Ми- 
лостивая // Вестник Северо-Кавказского федерального университета. - 2014. - № 1 (40). - С. 196-199.

Минченков, А. Г. Когниция и эвристика в процессе переводческой деятельности / А. Г. Минченков. - СПб. : Антология, 2007. - 256 c.

Пищальникова, В. А. Проблема идиостиля. Психолингвистический аспект / В. А. Пищальникова. - Барнаул : АГУ, 1992. - 74 с.

Реймерс, Н. Ф. Природопользование: словарьсправочник/Н. Ф. Реймерс. -М. : Мысль, 1990.-637 с.

Хализев, В. Е. Теория литературы / В. Е. Хализев. - М. : Высшая школа, 1999. - 398 с.

Хоружий, С. Комментарий / С. Хоружий // Улисс / Дж. Джойс. - СПб. : Азбука-классика, 2004. - С. 779-984.

Watzlawick, P. Menschliche Kommunikation / P. Watzlawick, J. H. Beavin, D. D. Jackson. - Bern : Huber Verlag, 2003. - 272 S.

\section{ИСТОЧНИКИ}

Махов - Джойс, Дж. ОдиссейЯ / Дж. Джойс ; пер. на рус. С. А. Махова. - М. : СФК «Инвест», 2007. $-695 \mathrm{c}$.

Хинкис, Хоружий - Джойс, Дж. Улисс / Дж. Джойс ; пер. на рус. В. А. Хинкиса, С. С. Хоружего. - СПб. : Азбука-классика, 2004. - 778 с.

Joyce - Joyce, J. Ulysses / J. Joyce. - London : Penguin Books, 2000. - 940 p.

\section{REFERENCES}

Alefirenko N.F. Poeticheskaya energiya slova. Sinergetika yazyka, soznaniya i kultury [The Poetic Energy of a Word. Synergetics of Language, Consciousness and Culture]. Moscow, Akademiya Publ., 2002. 394 p.

Babenko L.G., Vasilyev I.E., Kazarin Yu.V. Lingvisticheskiy analiz khudozhestvennogo teksta [Linguistic Analysis of a Fiction Text]. Ekaterinburg, Izd-vo Ural. un-ta, 2000. 534 p.

Bart R. Lingvistika teksta [Text Linguistics]. Tekst: aspekty izucheniya semantiki, pragmatiki i poetiki: Sb. statey [Text: Aspects of the Study of Semantics, Pragmatics and Poetics. Collection of Articles]. Moscow, URSS Publ., 2001, pp. 168-175.

Bakhtin M.M. Estetika slovesnogo tvorchestva [Aesthetics of Verbal Creativity]. Moscow, Iskusstvo Publ., 1986. 444 p.

Bolotnova N.S. Filologicheskiy analiz teksta [Philological Analysis of the Text]. Moscow, Flinta, Nauka Publ., 2007. 520 p.

Gasparov B.M. Yazyk, pamyat, obraz. Lingvistika yazykovogo sushchestvovaniya
[Language, Memory, Image. Linguistics of Language Existence]. Moscow, Novoe lit. obozrenie Publ., 1996. $352 \mathrm{p}$.

Genieva E.Yu. Kommentarii k «Ulissu» [Comments on Ulysses]. Inostrannaya literatura, 1989, no. 1, pp. 177-186.

Gurova Yu.I. Perevod. Vossozdanie vnutrenney smyslovoy programmy i edinogo smysla teksta kak osnova modelirovaniya protsessa perevoda [Translation. Reconstruction of the Internal Semantic Program and a Single Sense of the Text as the Basis for Modeling the Translation Process]. Saint Petersburg, Renome Publ., 2010. 239 p.

Dibrova E.I. Fenomeny teksta: kulturofilologicheskiy i psikhofilologicheskiy [Culturological and Psychophilological Phenomena of the Text]. Philologica, 1996, no. 10. pp. 2-5.

Dymarskiy M.Ya. Problemy tekstoobrazovaniya $i$ khudozhestvennyy tekst (na materiale russkoy prozy $X I X-X X v v$.) [Problems of Text Formation and the Fiction Text (Based on Russian Prose in $19^{\text {th }}-20^{\text {th }}$ Centuries)]. Moscow, URSS Publ., 2001. 328 p.

Kvinsi T. de. Ispoved anglichanina, lyubitelya opiuma [Confessions of an English Opium-Eater]. Moscow, Ladomir, Nauka Publ., 2000. 422 p.

Komissarov V.N. Sovremennoe perevodovedenie [Modern Translatology]. Moscow, ETS Publ., 2001. $424 \mathrm{p}$.

Lotman Yu.M. Istoriya i tipologiya russkoy kultury [History and Typology of Russian Culture]. Saint Petersburg, Iskusstvo-SPb. Publ., 2002. 768 p.

Milostivaya A.I. Rol printsipov sinergetiki v sovremennom perevodovedenii [The Role of Synergetic Principles in Modern Translatology]. Vestnik Severo-Kavkazskogo federalnogo universiteta [Newsletter of North-Caucasus Federal University], 2014, no. 1 (40), pp. 196-199.

Minchenkov A.G. Kognitsiya i evristika v protsesse perevodcheskoy deyatel'nosti [Cognition and Heuristics in the Translation Process]. Saint Petersburg, Antologiya Publ., 2007. 256 p.

Pishchalnikova V.A. Problema idiostilya. Psikholingvisticheskiy aspect [The Problem of Idiostyle. Psycholinguistic Approach]. Barnaul, AGU Publ., 1992. 74 p.

Reymers N.F. Prirodopolzovanie: slovarspravochnik [Nature Management: Dictionary]. Moscow, Mysl Publ., 1990. 637 p.

Khalizev V.E. Teoriya literatury [Theory of Literature]. Moscow, Vysshaya shkola Publ., 1999. 398 p.

Khoruzhiy S. Kommentariy [Comment]. Uliss [Ulysses]. Saint Petersburg, Azbuka-klassika Publ., 2004, pp. 779-984.

Watzlawick P., Beavin J.H., Jackson D.D. Menschliche Kommunikation [Human Communication]. Bern, Huber Verlag, 2003.272 p. 
С.В. Серебрякова, А.И. Милостивая. Семантическая эмерджентность как переводческая проблема

SOURCES

Joyce J. OdisseyYa [OdysseyI]. Transl. by S.A. Makhov. Moscow, SFK Invest Publ., 2007. $695 \mathrm{p}$.
Joyce J. Uliss [Ulysses]. Transl. by V.A. Khinkis, S.S. Khoruzhiy. Saint Petersburg, Azbuka-klassika Publ., 2004. 778 p. $940 \mathrm{p}$.

\section{Information about the Authors}

Svetlana V. Serebryakova, Doctor of Sciences (Philology), Professor, Head of the Department of Translation Theory and Practice, North-Caucasus Federal University, Pushkina St., 1, 355009 Stavropol, Russian Federation, svetla.na@mail.ru, http://orcid.org/0000-0001-5743-3227

Aleksandra I. Milostivaya, Candidate of Sciences (Philology), Associate Professor, Department of Theory and Practice of Translation, North-Caucasus Federal University, Pushkina St., 1, 355009 Stavropol, Russian Federation, amilostivaya@inbox.ru, http://orcid.org/0000-0001-5052-2622

\section{Информация об авторах}

Светлана Васильевна Серебрякова, доктор филологических наук, профессор, заведующая кафедрой теории и практики перевода, Северо-Кавказский федеральный университет, ул. Пушкина, 1, 355009 г. Ставрополь, Российская Федерация, svetla.na@mail.ru, http://orcid.org/0000-00015743-3227

Александра Ивановна Милостивая, кандидат филологических наук, доцент кафедры теории и практики перевода, Северо-Кавказский федеральный университет, ул. Пушкина, 1, 355009 г. Ставрополь, Российская Федерация, amilostivaya@inbox.ru, http://orcid.org/0000-0001-5052-2622 